\title{
RUSSELL AND DEWEY ON THE PROBLEM OF THE INFERRED WORLD
}

\author{
Josh ZaSLOW \\ Philosophy / McMaster U. \\ Hamilton, on, Canada L8s 4L6 \\ ZASLOWJJ@MCMASTER.CA
}

In this paper I explore the little-known first debate, in I9I4-I9, between John Dewey and Bertrand Russell over the problem of the external world. After outlining their respective arguments, I show how Dewey's criticisms of Russell miss the mark. Although these thinkers largely speak past one another, I argue that Dewey's theory of inference is not only crucial to this exchange but also reveals what is at stake in their disagreement. Unfortunately, Dewey himself never explicitly invoked his account of inference during this short-lived and ultimately fruitless exchange with Russell. Had he done so, the crucial issue of their differing criteria of justification would have been raised and their exchange could have been more productive.

I

$\mathrm{n}$ their respective works "On Our Knowledge of the External World" (1914) ${ }^{\mathrm{I}}$ and "The Existence of the World as a Problem" (1915), ${ }^{2}$ Bertrand Russell and John Dewey debate the philosophical significance of the problem of the external world. Briefly (and crudely) stated, for Russell the problem of the external world is not whether it exists, but whether, or to what degree, the inference from sense-data to objects can be justified. ${ }^{3}$ While Dewey sees the very statement of this

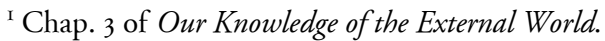

${ }^{2}$ Philosophical Review 24 (1915): 357-70. Revised and reprinted as Chap. II of Dewey's Essays in Experimental Logic (1916). I shall quote from John Dewey, The Middle Works, I899-I924, Vol. 8: I9I5, ed. Jo Ann Boydston (Carbondale: Southern Illinois U. P., 2008).

${ }^{3}$ Although Russell distinguishes between sense-data and sensations in the first edition of Our Knowledge, in the second edition he no longer sees the distinction as "valid" or even "necessary" for stating his problem, p. 83. He directs the reader to The Analysis of Mind, pp. I4Iff., for his arguments concerning this distinction. 
question to be incoherent, Russell contends that Dewey's criticisms misinterpret his project and as a result miss the mark. Although a great deal of critical attention has been directed toward the Russell-Dewey relationship, particularly Tom Burke's Dewey's New Logic: a Reply to Russell, this work, among others, focuses on Dewey and Russell's lengthier debate starting in $1938 .{ }^{4}$ Unfortunately, the earlier important debate, which is the subject of the present article, has hitherto escaped much attention. $^{5}$

Although detailing their earlier debate naturally involves elaborating the respective arguments that Dewey and Russell direct at one another, in what follows I will not be taking these as my sole guide. Instead I will attempt to clarify this exchange by framing it in terms that are to some degree different from those the thinkers themselves employ. In particular, I will pursue one of Russell's suggestions that Dewey (unfortunately) doesn't pursue, namely his claim that the problem of the external world is better stated as the problem of the inferred world. When the problem is framed in these terms, I show that there is a degree of contact with Dewey's account of inference - an account, I argue, that Dewey failed to adequately draw upon in his criticism of Russell. My modest goal is to shed new light on what is at stake in their exchange.

Before proceeding, it is crucial to note that the problem of the external world detailed in Russell's chapter, "On Our Knowledge of the External World", is not an attempt to raise sceptical doubts regarding our knowledge of the external world. His concern is rather to investigate the degree to which the inference from sense-data to external objects can be justified. This statement is admittedly tentative: Russell proceeds by providing an initial statement of the problem, refines it by introducing new distinctions, and ultimately formulates a more adequate and nuanced version of the problem to be resolved. The two major distinctions that frame his discussion are those between (i) primitive and derivative beliefs, and (ii) hard and soft data. I will discuss these in turn, as the latter distinction emerges from considering the former; yet attending to both distinctions is crucial for understanding Russell's project.

${ }^{4}$ Samuel Meyer's edited volume on Dewey and Russell's exchange omits this earlier debate (Dewey and Russell: an Exchange [New York: Philosophical Library, 1985]).

5 William Barrett notes the exchange and broadly sides with Dewey when critiquing Reichenbach in "On the Existence of an External World", Journal of Philosophy 36 (22 June 1939): 346-54 (at 346). 
The problem of the external world, Russell claims, arises from within our current set of accepted beliefs. Starting with a methodological note, he says "our investigation starts from what may be called 'data,' by which I mean matters of common knowledge, vague, complex, inexact, ... but yet somehow commanding our assent as on the whole and in some interpretation pretty certainly true." 6 The difference between this project and the sceptical argument provided in Descartes' Meditations, for example, should be clear. While Descartes proceeds by doubting all of our settled beliefs by invoking the possibility of an evil demon to establish that a gap exists between our sense-data and objects, for Russell establishing the existence of such a gap requires little more than a critical reflection on our beliefs.

To initiate his version of the problem, Russell makes a preliminary distinction between primitive and derivative beliefs $\left(O K E W_{2}, \mathrm{p} .75\right)$. For instance, if I believe that someone is at my front door, for my belief to be warranted might require my having heard the doorbell ring. This belief would be derivative since it depends upon the further belief that what I heard was, in fact, the doorbell. In contrast, my belief that I heard the doorbell does not depend upon further beliefs, but simply the fact that I experienced the sound. In this sense, my belief that I heard the doorbell is primitive. Of course, that we might identify some beliefs as primitive does not imply that I could not misidentify the sound and thereby form a false belief about my experience. I certainly could and often do. However, this illustrates that the distinction between primitive and derivative beliefs is not a matter of their relative infallibility. The purpose of Russell's contrast is primarily to illustrate a justificatory difference: in justifying my belief that I heard the doorbell, I do not need to invoke further beliefs, but simply the fact that the sound occurred.

Having laid out this initial contrast, Russell complicates his distinction by noting that beliefs that are primitive (or derivative) can be primitive (or derivative) in either a psychological, or a logical, sense. In terms of this more fine-grained categorization, the belief that somebody is at the door would be a case of a logically primitive, yet psychologically derivative, belief. It is psychologically derivative because it is predicated upon our having associated (in general) the ringing bell with the presence of visitors. At the same time, it is only in rare circumstances that we can be

${ }^{6} \mathrm{OKEW}_{2}$, pp. 70-IO5 (at 72). 
said to have actually and actively inferred the presence of a visitor from the occurrence of the sound: most of us are simply habituated to react to the latter as a sign of a visitor. For this reason, Russell considers this belief, at least under ordinary circumstances, to be logically primitive since it is immediately formed, i.e., the belief in question is not arrived at as the result of a conscious and deliberate inference.

Russell considers the class of logically primitive but psychologically derivative beliefs particularly interesting because our confidence in such beliefs is, from a logical point of view, dependent upon how well they can be justified in terms of beliefs that are more psychologically primitive. To the degree that we find ourselves unable to do this, he contends that our confidence in such beliefs should be diminished. It is this feature of logically primitive and psychologically derivative beliefs that provides the basis for Russell's initial statement of the problem of the external world: he considers our belief in persistent objects to have arisen as the result of what one might call habituation.

Just as we rarely arrive at beliefs about other people's emotions through any explicit inference, Russell thinks a similar case can be made regarding our beliefs in objects such as chairs and tables. In such circumstances, these common-sense beliefs are logically primitive. However, as beliefs in such objects have in most cases arisen through our mere engagement with the world, they are also psychologically derivative. Because our beliefs in objects are of this kind, Russell sees us as having good reason, not necessarily to doubt the veracity of these beliefs, but at least to consider them to be on weaker footing than we ordinarily suppose. In even so ordinary a claim as "That is a chair", he thinks we too quickly assume that what we have before us is a persistent object; that it not only exists when we are not there to observe it, but also that the very object persists in each of our encounters with it. Although beliefs such as these are ubiquitous, Russell considers these to be unjustified unless we can provide an explicit argument for our general belief in objects (p. 77).

All of these considerations are tantamount to saying that through scrutinizing our stock of beliefs we discover that some have better claim to certainty than others. As Russell puts it, "although data can only be criticized by other data, not by an outside standard, yet we may distinguish different grades of certainty in the different kinds of common knowledge" (p. 74). Through a critical assessment of our beliefs he thinks that we discover that some of our common-sense beliefs are on less certain footing than we normally suppose. More importantly, through this pro- 
cess we simultaneously discover that some of our beliefs are more difficult to doubt. The examples of beliefs that Russell identifies as most resistant to such scrutiny include beliefs about sensations and logical truths. We do not need to provide an argument for our claims about what we see, or sense in any way, because "as far as their momentary existence is concerned, no further argument is required" aside from their occurrence (p. 77). Equally, we would be hard pressed to give up our confidence in any valid rule of inference.

Russell formulates a somewhat loose distinction between hard and soft data based upon his discussion of relative degrees of certainty amongst our beliefs. This distinction is crucial for his problem of the external world as it provides the terms in which he ultimately states his problem. He elaborates this contrast between hard and soft data as part of the process of scrutinizing our beliefs. He says, "I mean by 'hard' data those which resist the solvent influence of critical reflection, and by 'soft' data those which, under the operation of this process, become to our minds more or less doubtful" (pp. 77-8). At the harder end of this spectrum we find "the particular facts of sense, and the general truths of logic" (p. 79), while the softer end of this spectrum includes, for example, our beliefs about the objects that we seem to sense, as well as the more general belief that these objects exist in a world independent of ourselves. Given this rough structure of our beliefs, Russell finally poses his question: "Can the existence of anything other than our own hard data be inferred from the existence of those data?" (p. 80). This question is his problem of the inferred world.

While this question might seem radically different from the characterizations of the problem that I provided earlier, it is crucial to see how they are related. Originally, I claimed that Russell's question was whether, or in what way, the inference from sense-data to objects is justified. Although these are the initial terms of Russell's problem, the issue is subsumed in this later statement. The question of the degree to which sense-data justifies our belief in persistent objects is a particular case of the broader, and more pressing, matter of the relation of hard to soft data, and the extent to which the latter can be inferred from the former.

Before further elaborating his problem, Russell suggests that it is important to consider what his problem is not. I will follow his advice by examining how Dewey's criticisms fail to address Russell's actual project. This discussion will provide an avenue for reaching a clearer understanding of Russell's problem, and provide initial grounds for understanding 
what Dewey found objectionable about it.

One of Dewey's primary criticisms of Russell's statement of the problem of the external world is that it rests upon a bad psychology. When Russell speaks of an inference from sense-data to objects, or even from hard to soft data (a contrast in which sense-data are considered hard), Dewey wants to emphasize that this runs contrary to our actual psychological and epistemological situation. Our knowledge of sense-data is something that, psychologically speaking, both arises through and depends upon our complex interactions with objects. Russell himself concedes this point, as he considers that encounters with phenomena such as the refraction of light in water illustrate that there is a distinction to be made between objects and our perception of them. However, in identifying sense-data as psychological primitives, and our beliefs about objects as a case of derivative knowledge, Dewey charges that Russell puts the cart before the horse: our knowledge of sense-data is itself dependent upon a great deal of knowledge that goes beyond pure perception, such as the knowledge disclosed by the study of physiology or optics.

Although this might seem to be particularly damning criticism, it misses the target: Russell explicitly concedes all of these psychological facts. If anything, they are for him all clear cases of psychologically derivative knowledge, and therefore in need of surer footing. Whatever history might be involved in our coming to know and form beliefs about our sense-data, Russell considers such details to be irrelevant to his problem. This is no different than the fact that the history of how we come to know the laws of valid inference is irrelevant to establishing their validity. Russell's point is that once we have such beliefs in our inventory, they possess a certainty that other beliefs lack. Whatever might be said of the training involved in making claims about our perceptions, the point that Russell insists upon is that in justifying claims about how things seem to us, we remain on much safer ground than when we make claims about how things really are. In posing his problem of the external-or inferred-world Russell is attempting to determine how safe the ground of such claims can be made.

Because of his insistence upon the psychological issues at hand, Dewey's target might be seen as largely directed toward how Russell frames his problem, rather than the problem itself. However, the deeper and more important challenge Dewey raises is whether Russell's problem of 
the external world is a genuine question. ${ }^{7}$ If Russell's question is whether, or to what extent, our hard data serve as evidence for our soft data, Dewey thinks that the very statement of the problem carries an implicit, affirmative answer to the question at hand (ibid.). He draws attention to the fact that in stating his question, Russell invokes the distinction between appearance, or the way things seem to be, and reality, or the way things are. For Russell, the former is paradigmatically hard data, the latter a case of soft data.

While this distinction is not itself problematic, Dewey contends that Russell's use of it is illicit. To discuss the way things seem to be, he charges, can only have substance if it has a genuine contrast. In other words, we can only talk about the way things seem to be if we can already contrast this with the way things actually are. Yet, while Dewey admits that identifying certain data as sensory might simply be an unfortunate use of words, and even suggests that the question of the external world might be formulated without such language, he remains dubious. $\mathrm{He}$ sceptically asks, "Is it possible to institute even a preliminary disparaging contrast between immediate objects [i.e. sense-data] and a world external to them unless the term 'sensory' has a certain effect upon the meaning of immediate data or objects?” (p. 85). Unfortunately, a decisive answer to such a question is difficult, if not impossible, to provide. As a result, Dewey's subsequent comments largely attempt to show how information beyond the purely sensory might be implicitly involved in stating the problem.

The dubiousness of this attempted critique becomes clearer when Dewey's psychological criticism is reformulated in terms of Russell's preferred terminology of hard and soft data. If we were to translate Dewey's criticism into these terms, his question would be whether identifying some data as hard implies the existence of soft data. Dewey might contend that if such a contrast is legitimate, then our ability to identify some data as hard obviously requires that we have some knowledge of soft data against which to contrast it. However, it must be emphasized that whether hard and soft data are interdependent or not, this is not Russell's question. Russell's concern is to ask what relation our hard data bears to soft data, fully conceding that knowledge beyond purely hard data is being invoked in setting up this question.

${ }^{7}$ Dewey, Middle Works 8: 84. 
Russell restates his problem in his review of Dewey's Essays in Experimental Logic, ${ }^{8}$ in a way that is more clearly immune to this criticism. After noting that our beliefs can be loosely sorted into the harder and softer, he states, "the question arises: what inferences are justified by this store of particulars and facts [i.e., hard data]?" (Papers 8: 150). None of the criticisms provided by Dewey address the statement. However, the statement is telling because it clarifies Russell's problem. It reasserts that his question concerns a certain class of inferences, rather than being identical with the traditional problem of the external world. It also helpfully reasserts that his aim is a justificatory one-he is concerned to examine the extent to which our hard data justifies our beliefs about soft data.

Having specified Russell's project in "On Our Knowledge of the External World", I will now explore the extent to which Dewey's account of inference can be treated as relevant to their exchange. In his response to Dewey, Russell concedes that he (Dewey) has the tradition of logical theory on his side because "he takes the view-for which there is much better authority than for mine-that logic is concerned with thought" ( $\mathrm{p}$. I34). This statement is preceded by an instance of Russell's frequent claim that Dewey's logical theory is better described as "part of psychology" (ibid.). In fact, he goes on to make the stronger claim that what Dewey calls logic "does not seem ... to be a part of logic at all" (ibid.). At best, Russell takes Dewey to be misusing the word "logic" and, at worst, committing the philosophical sin of psychologism.

From Dewey's perspective, however, this way of representing his project is curious because, although he concedes that he is not discussing logic in the same sense as Russell, he nonetheless insists that there is some common ground in their projects. Dewey's logical theory is intended to be used to discuss the subject in a sense wider than Russell's. Indeed, he considers Russellian logic, or the theory of formal inference, to fall under his wider discussion of inference. ${ }^{?}$

${ }^{8}$ Russell, "Professor Dewey's Essays in Experimental Logic", Papers 8: 132-54. Reprinted from The Journal of Philosophy, Psychology, and Scientific Methods I6 (1919): 5-22. Reprinted in Dewey and His Critics, ed. Sidney Morganbesser (New York: Journal of Philosophy, 1977), pp. 23I-52.

9 On this matter I am in agreement with Tom Burke, who claims "The reasons why Russell's notion of nearly immediate knowledge is unacceptable to Dewey ultimately hinge on differences in their respective conceptions of logic" ("Dewey and Russell on the Possibility of Immediate Knowledge", Studies in Philosophy and Education I7 [1998]: I49- 
To understand what this "wider discussion" involves, it is worthwhile to note that Dewey introduces his later book, Logic: the Theory of Inquiry, by distinguishing the proximate from the ultimate subject matters of logic. Although we certainly know that logic is concerned with the validity of inference in some sense (a discussion that Dewey considers the proximate subject matter of logic), he does not think that we have an adequate account of what logic-i.e. the study of valid inference-is $u l$ timately about. In this work Dewey develops the position that the ultimate subject-matter of logic is a certain kind of behaviour; in particular, the behaviour involved in inquiry.

To this extent, Dewey does not see his project to be at odds with what Russell considers logic, but rather he intends to provide a complementary account. On Dewey's account, the theory of formal inference-what Russell considers logic — is a field that can be developed independently of Dewey's account of the ultimate subject matter of this study. He is explicit that "it is possible ... to deal with what was called proximate subject-matter [the theory of formal inference] without raising this question [i.e. the question of what sort of things inferences are]."IO As such, the differences between Deweyan and Russellian logic, at least from Dewey's perspective, are nothing more than a matter of emphasis and purpose.

Despite his interest in this wider context of inference, it must be noted that Dewey does not treat all cases of inference on a par. In fact, he employs a distinction, albeit a loose one, between formal and material inferences. Although he does not provide a strict definition of either formal or material inference, it is sufficient for my purposes to note that his position is that "the formal development is a specialized offshoot of material thinking." Material thought, for example, refers to inferences as we make them in our everyday interaction with our environment,

53 [at I50]). However, unlike Burke, I don't take this difference to be helpfully explained in terms of differing conceptions of experience. Although Dewey pursued this tack, he erred in taking Russell to be providing an account of experience on the model of the British empiricists.

Io Dewey, The Later Works, I925-1953, Vol. 12: 1938: Logic: the Theory of Inquiry, ed. Jo Ann Boydston (Carbondale: Southern Illinois U. P., 199I), p. 31. Reprint of Logic: the Theory of Inquiry (New York: Henry Holt, 1938).

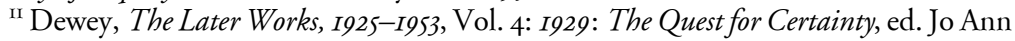
Boydston (Carbondale: Southern Illinois U. P., I988), p. 129. Reprint of The Quest for Certainty (New York: Minton, Balch, 1929). 
while formal inference (as he understands it) is the kind of reasoning present in fields such as mathematics. However else the contrast should be characterized, the fact that Dewey sees formal inference as a refinement of other cases of inference suggests that he thinks that formal inference can be accounted for by this broader understanding.

On Dewey's account, the basic kind of inference involves an organism taking an object or event as a sign of further occurrences. The behaviour of a beagle when scent-tracking exemplifies such behaviour. Although it is not done consciously, the beagle can be said to make an inference, or at least engage in inference-like behaviour, insofar as it takes the scent as a sign-i.e. to the extent that it behaves towards the scent as signifying the presence of a rabbit. Whatever history or training was involved in the dog coming to associate the scent with the animal, what is important is that the inference from scent to rabbit is warranted because of the physical connection holding between the two. Indeed, Dewey thinks that such causal connections, what he calls involvements, allow an object or event to function as a sign and to sustain this class of warranted inferences.

Although Dewey initially describes inference in such frankly biological terms, this should not be taken to imply that he sees such cases to be exhaustive or even definitive of all cases of inference. Indeed, he admits there is an important difference between the behaviour of animals in their inferences and that of humans in theirs. Humans, he thinks, perform inferences in terms of symbols as well as signs (and generally do these consciously). In contrast to signs, which Dewey sees as representing further occurrences in virtue of their signification, he thinks that symbols function by virtue of their meaning. To illustrate the distinction, smoke functions as a natural sign of fire because the former is a product of combustion, while "smoke", the word, serves as a symbol for the physical existence of smoke because of its meaning. This symbol, in turn, implies (via certain mathematically stated physical laws) certain conditions of pressure, temperature, the presence of certain chemical elements, etc. On the more abstract end, similar cases can be constructed regarding mathematical symbols. Whereas the validity of inferences involving signs depends upon the involvements - causal connections that hold between sign and signified-on Dewey's account, the adequacy of inferences involving symbols is partly due to the relations of logical (or, in Russell's terminology, "material") implication holding between symbols themselves, in the sense that calling somebody a "bachelor" implies that he is 
an unmarried male.

Having briefly described the contrast between inferences using signs and symbols, I do not intend to suggest that Dewey's distinction between formal and material inferences cleanly maps onto his distinction between symbols and signs, or is even identical with the differences between inferences rooted in implications and inferences predicated upon involvements. For present purposes, what matters is that Dewey explicitly identifies formal inferences as a subset of inferences involving symbols. "Formal logic represents an analysis of exclusively symbolic operations; it is, in a pregnant and not external sense, symbolic logic" (p. I29). What is "symbolic" about symbolic logic, on his view, is not merely that symbolization is employed in the study of logic in order to more clearly state logical theorems. More fundamentally, Dewey thinks that symbolic, or formal, logic is an inquiry into the relations that hold between abstract logical symbols themselves. This, for example, includes discussion of the role played by operations of conjunction, disjunction, conditionals and so forth, in the context of sets of propositions.

Having provided a brief account of Dewey's views on inference, we are now a good position to relate this account to Russell's problem of the inferred world. When Russell's problem is stated in terms of the validity of the inference from sense-data to objects, Dewey's response is that there is an important sense in which we don't need to make such inferences. For better or for worse, taking our sense perceptions as signs of objects is so well established that our response to the former is fused with our response to the latter. In such cases, Dewey wants to emphasize, "such fusion or consolidation is precisely not inference. As matter of fact, such 'fusion' of qualities, given and formerly inferred, is but a matter of speaking." ${ }^{2}$ Even if we, like Russell, wish to speak of some form of implicit inference occurring in these cases, for Dewey that we make such inferences is obvious in the sense that we not only do implicitly make such inferences whenever we take our sense-data as signs of objects, but, further, we know that in all but extraordinary circumstances (such as hallucination) these inferences are also justified.

Although Dewey is not so explicit on this matter, his invocation of psychology, aside from being part of his attempt to undermine the very

${ }^{12}$ Dewey, "The Logic of Judgments of Practice”, Middle Works 8: 49-64 (at 53). Reprinted from Journal of Philosophy, Psychology, and Scientific Methods I2 (I915): 505-23, 533-43. Revised and reprinted in Essays in Experimental Logic. 
statement of Russell's problem, also serves to illustrate that we already have an adequate account of what makes such inferences generally warranted, and it is due to nothing more than the causal connection between sense-data and objects. That Dewey so often invokes psychological facts in responding to Russell suggests that he reads Russell's demand for a justification of this inference in such material terms. That is, we take our sense-data as signs of objects, and this kind of inference is generally warranted because of the causal connection between the two. Yet, as I have emphasized, the psychological facts that Dewey appeals to are not ones that Russell disputes. Russell concedes them, and nonetheless considers his project unchanged. His question is not about whether a causal connection holds between sense-data and the world: he never denies this. Russell's concern is something else.

While Dewey's theory of material inference isn't applicable to Russell's project, this does not end the matter: Dewey also provides an account of formal inference which is prima facie closer to what Russell means by the inference from hard to soft data. Understood in this way, Russell's question about the inference from hard to soft data-his problem of the inferred world-is not about inferences we do make: his concern is rather about what further claims our hard data can support, not in the sense of being materially warranted, but rather in the sense of logical implication. This problem can be clearly stated in mathematical terms. If we take formal rules of inference and perception as our postulates, what, Russell asks, are their corollaries? If this is indeed Russell's project, it is not clear that Dewey would necessarily have a problem with the project.

Tom Burke makes the following claim regarding Dewey and Russell's post-I938 exchange, which is no less apt for this initial debate:

Much of the antagonism between Dewey and Russell might have been avoided, or at least toned down to more tolerable levels of intensity, if Dewey had not overstated his rejection of such developments [in formal logic] as to their adequacy or their being appropriate to the study of logic.... Dewey was not helping his own cause by not showing any appreciation of the significance of the view he was criticizing. ${ }^{\text {I3 }}$

\footnotetext{
${ }^{13}$ Dewey's New Logic: a Reply to Russell (Chicago: U. of Chicago P., I994), p. 266.
} 
To acknowledge this is not to diminish the importance of their disagreement, but it reveals that Russell is especially perceptive when he suggests in his I9I9 review, "No doubt he [Dewey] feels that I attach too little importance to matters which he regards as vital. Th[e] differing estimate of relative importance is, I think, the main source of differences between him and me" (Papers 8: 134).

Although Dewey is certainly right that there is no genuine problem of action because we $d o$ act as if there is such a world-i.e., we take our hard data to have certain implications for our softer beliefs-Russell would not disagree on this point, but would go on to ask about how strongly this connection can be justified.

If Russell is indeed looking for a deductive argument from hard data to soft, there seems to be nothing a priori to rule out the possibility of such an argument, and Dewey's criticisms do not suggest an affirmative or negative answer. However, Dewey's overall attitude towards Russell's project suggests that he is dubious about the possibility of such a proof. That he puts so much weight upon the psychology of inference suggests that he thinks that nothing more is required in answering or disposing of Russell's problem. But as we have seen, although Russell might accept the psychology, he questions its relevance.

While Russell initially sets up his problem of the external world by invoking a gap between sense-data and objects, it is crucial to remember that these are not the terms in which he ultimately poses his question. Unfortunately, to the extent that Dewey takes the formulation of Russell's problem as his target, he misses the real question. Given his own resistance towards the language of sense-data empiricism, it is understandable that Dewey takes Russell's use of that language to be yet another iteration of the traditional problem. This is not to justify such a misreading: it blinds Dewey to the fact that Russell is only using this terminology in his initial set-up of his problem. However, the contrast between sense-data and an external world ultimately has little bearing upon Russell's problem of the inferred world.

When Russell frames his question in terms of the justification of our inference from hard to soft data, Dewey's criticisms lose their traction. Although this project retains some contact with Dewey's theory of inference, it is apparent that in his criticisms of Russell, Dewey wants to emphasize that we know a great deal about the material conditions that make the inference from sense-data to objects a valid one. Since Russell's question concerns a deductive argument from hard to soft data, Dewey's 
sceptical attitude amounts to little more than a doubt that such an inference is either possible or necessary. However, it is impossible to make such a valuation or dismissal a priori. ${ }^{\mathrm{I}}{ }^{\mathrm{O}}$

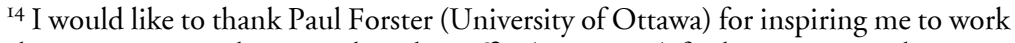
on this interesting exchange and Nick Griffin (McMaster) for his support and encouragement. Finally, I would like to thank the Editor for his comments. 